\title{
Broken promise
}

\section{Brian Deady, MD*}

In the emergency department (ED), the trauma team had assembled upon receiving a hurried notification from dispatch. Details were scant: single-occupant car into cement abutment, driver conscious, and firstresponders working on extrication.

At the head of the bed stood the emergency physician (EP), while the physician trauma team leader (TTL) was at the foot. The nurses, resident, respiratory therapist (RT), and ancillary staff were there, too.

The staff had done it many times before, and there was an air of confidence born of the knowledge that each member could rely on the other. The EP made a few lame jokes to keep the team loose. Waiting is always difficult, even if you are ready.

Then, the ambulance attendants sprang through the resuscitation room doors, looking red-faced and perturbed. The patient was pale and breathing rapidly, but conscious. One of the paramedics, with beads of sweat visible on his brow, loudly proclaimed the history while the others prepared to move her to the hospital gurney, "18-year-old female, restrained driver in a car v. bridge, probably high speed. Twenty-minute extrication by fire crew, patient awake, and responsive throughout. Complains of chest, back, and lower abdominal pain. On scene, blood pressure 86/50 and pulse 118. Good bilateral air entry. Abdomen tender. Single 20 gauge [intravenous] IV and tranexamic acid (TXA) 1 gram bolus given, followed by $500 \mathrm{cc}$ saline. No meds, no allergies."

"Start the TXA infusion, 1 gram over 8 hours, please," called out the TTL, as the team set to work.

As the paramedics placed the patient on the ED gurney, she abruptly called out. "Help me; I'm going to die!"
The emergency physician felt his abdomen tighten as if he had been kicked in the midsection. He placed his hand over his own belly and at the same time noticed the resident raise herself up and down on her toes and then roll her shoulders. He heard a snap, snap as the TTL pulled skittishly at his gloves.

The resident had begun to work her way through the primary survey as a nurse called out, "Blood pressure 70/40. Pulse 132."

"Initiate the massive transfusion protocol and get that second IV in. Transfuse two units unmatched packed red blood cells stat," the TTL called out. "Stabilize and [computed tomography] CT, if possible. Could the unit clerk get the trauma surgeon down here and call the operating room to tell them to get ready. Intubation to proceed once we plump up her blood pressure. Let's go, go."

At the head of the bed, the emergency physician flexed his neck to gaze directly into the patient's eyes. He had a fleeting thought that she would perceive his face upside down, rendering him clownish. He pushed back against the anxiety gnawing at his gut and stroked her cheek with his gloved finger. Put yourself in her place, he thought, without willfully forming the words. He addressed her, with a tranquility he did not feel and a vocal tenderness he might have reserved for one of his own daughters. He tucked his head down further to whisper in her right ear.

"Listen, sweetie. We are all here for you, a whole team of experienced people. You're not going to die. We won't let you." He stroked her cheek one last time, "Promise, kiddo."

Had the patient felt hope, some measure of relief? He could not be sure. He stood up to check that the RT had everything ready.

From *Clinical Associate Professor, Department of Emergency Medicine, University of British Columbia; and Emergency Department, Royal Columbian Hospital, New Westminster, BC.

Correspondence to: Dr. Brian Deady, MD, Emergency Department, Royal Columbian Hospital, 330-East Columbia Street, New Westminster, BCV3L 3W7; Email: brian_deady@shaw.ca

(c) Canadian Association of Emergency Physicians

CJEM 2019;21(2):306-307

DOI 10.1017/cem.2018.480 
The resuscitative measures had begun to nudge her vital signs in a favourable direction. The resident had pushed rapidly through the primary survey and established the presence of a rigid abdomen and an unstable pelvis, with preserved ability to move her hands and feet. The patient's pelvis had been bound with a sheet. The resident was now wielding an ultrasound probe.

"The patient is young, she has loads of physiological reserve, we will pull her through," are the words the EP would have said to himself if he had had the benefit of time. As it were, he moved without conscious reflection, ignoring the niggling little sensation running up his spine that concealed an ominous premonition.

He called out his primary and backup intubation plans and requested appropriate pharmacological agents. When all was in order, he proceeded, with the RT at his side. The endotracheal tube was placed on the first pass using a video laryngoscope, and a colorimetric change was observed on the disposable $\mathrm{CO}_{2}$ detector.

The RT took control of the endotracheal tube as he auscultated the patient's chest. With the RT squeezing the bag-valve-mask apparatus, the patient's thorax rose and fell with equal bilateral air entry. Then, the continuous end-tidal capnography reading became available that confirmed successful endotracheal tube placement. He watched the RT connect the patient to the ventilator. A quick look at the vital signs on the monitor, and he called for a portable chest X-ray.

He stepped away from the head of the bed and briefly stood to watch the patient and the team. It occurred to him that the sentient part of the patient was suspended in a fog of anesthesia and the to-and-fro pumping sounds of the vent. Time, her time, was now measured in the electronic blips and digital beeps of a screen.
He then became briefly vertiginous, as a vexing tonal dissonance rang out from the cardiac monitor. The team scrambled to adjust the treatment course and he rejoined the resuscitative efforts, the taste of regret rising in his throat like bile.

Darkness had descended rapidly upon her, and then, gradually, she felt herself emerging, suspended, as if in a dreamy fog. It was not a dream though; she knew that just as she had known the words spoken in her ear were heartfelt but false.

It was the warmth these words conveyed that had meant so much to her. The reaching out, the human contact, and the caring. She had felt comforted as her loneliness dissolved, and she now accepted that her journey was nearing its completion.

As she moved to this ending, she experienced a deep connection to her family: her mother, her father, and her two younger brothers. She recalled a gradeschool friend, from whom she had grown apart. She thought of a teacher who had influenced her and helped instill self-confidence. She felt only love, pride, and happiness.

She suddenly realized that she had one final task to complete before leaving. He looked so forlorn, this whispering upside-down man. She stretched out her hand, and she reached and reached. She just could not quite touch him.

"It's okay," she wanted to say. However, the end came too soon, and she was gone.

Keywords: blunt trauma, empathy, stress

Competing interests: None declared. 